\title{
Substance misuse as a marker of vulnerability among male prisoners on remand
}

\author{
DEBORAH BROOKE, CAECILIA TAYLOR, JOHN GUNN \\ and ANTHONY MADEN
}

\author{
Background More treatment for \\ substance misuse should be provided \\ within prisons.
}

\begin{abstract}
Aims To examine differences between prisoners on remand with substance misuse problems and other prisoners on remand.
\end{abstract}

\section{Method Random selection and interview of unconvicted male prisoners ( $n=750$, a $9.4 \%$ sample), plus examination of the prison medical record.}

Results Of the sample of 750, 253 subjects (33.7\%) reported either drug- or alcohol-related health problems or dependency. Compared with other prisoners on remand, they reported more childhood adversity, conduct disorder, self-harm, past psychiatric treatment and current mood disorder, and had fewer qualifications, were more likely to be unemployed and have more housing difficulties.

\section{Conclusions One-third of unconvicted men in prison report substance-related problems, and these are a marker for vulnerability within a disadvantaged population. Health care providers should involve this group in treatment and rehabilitation, both inside prison and following release.}

Declaration of interest The study was funded by the Home Office Research and Planning Unit, for the Directorate of Health Care. The views expressed are the authors' own.
Remand prisoners constitute about onefifth of the UK prison population (Home Office, 1994). They are unconvicted, awaiting trial. The data reported here were obtained from the first survey of the prevalence of mental disorder among remand prisoners in England and Wales (Maden et al, 1996). We have reported that $23 \%$ of prisoners on remand at interview requested help with substance misuse (Brooke et al, 1998). In brief, 236 of 750 (31.5\%) male prisoners on remand, chosen at random, were allocated an ICD-10 (World Health Organization, 1992) diagnosis of dependency on one or more than one substance. Of these, $73(10 \%)$ were dependent on opiates, $81(11 \%)$ were dependent on stimulants and $91(12 \%)$ were dependent on alcohol. Here, we describe the characteristics of male prisoners on remand whose substance misuse caused them health problems, including dependency, and compare these characteristics with those of other prisoners on remand.

\section{METHOD}

The random selection of a previously calculated number of subjects from registers in 16 prisons across the country, stratified by location in the prison, and the components of the semi-structured interview, have been described previously (Brooke $e t$ $a l, 1996)$. The following self-reported data were collected: demographic and clinical characteristics (childhood adversity; delinquency; deliberate self-harm; psychiatric treatment, including substance misuse services; mental state; and contact with prison health care), forensic histories, and details of street drug use during the 6 months before their imprisonment. For each substance, subjects described whether they had used it 'occasionally' (less than 3-4 days per week) or 'daily/almost daily'. All those who reported using opiates or stimulants on a daily/almost daily basis were asked about symptoms of dependency syndrome as described in ICD-10. The CAGE questionnaire (Mayfield et al, 1974) was used to screen for alcohol dependency (ICD-10 code 10.2).

On the basis of these data, subjects were grouped into two categories.

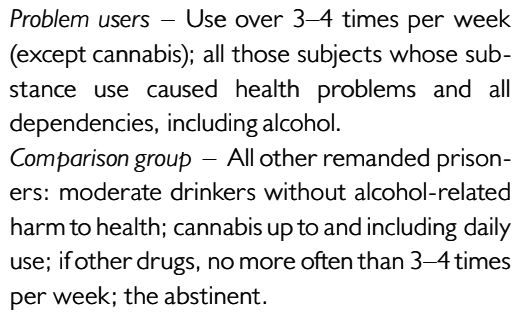

Subjects completed the SF36 questionnaire (Ware \& Sherbourne, 1992; McHorney et al, 1993) to give an indication of their general health.

Comparisons between the two groups were carried out using $\chi^{2}$ and $t$-tests, as appropriate, in SPSS for Windows. (Copies of the interview schedule are available from the first author upon request.)

\section{RESULTS}

We interviewed 750 subjects, representing a 9.4\% sample of the 7973 men held on remand on 31 December 1992. The average refusal rate was $18 \%$ (range $4-31 \%$ ). Of the 750 (average age 28 years, median 25, range 16-61), $207(28 \%)$ reported that they had not used any street drugs in the 6 months preceding their arrest, and that they were, at the most, social drinkers; $283(38 \%)$ reported 'occasional' use of drugs (i.e., less than 3-4 times per week). These 490 subjects comprised the 'comparison' subsample.

Ninety-one subjects $(12 \%)$ were solely dependent on alcohol. A further 162 $(22 \%)$ described themselves as heavy users of, or dependent on, one or more substances. These 253 subjects comprise the 'problem users' subsample. Seven subjects were unable to describe their levels of drug use.

\section{Demographic characteristics}

Of the 750 men, 585 (78\%) were Caucasian. The average age of the comparison subjects was 28.0 years (s.d. $=9.58$ ), so that they were older than the problem users (average age 26.5 years; s.d. $=7.31 ; t=2.32$, d.f. $=638.9, \quad P=0.021)$. Of the whole sample, $350(47 \%)$ had never married; 
$211(28 \%)$ described themselves as married or cohabiting. Problem users were less likely to have been living in their own home, or with their own family, before arrest, and were less likely to be returning to their own home or family after release (194 of 253 (77\%) problem users previously living thus, compared with 420 of $490 \quad(86 \%)$ comparison subjects: $\chi^{2}=9.49, P=0.0021 ; 161$ of $253(64 \%)$ problem users expected to return, compared with 349 of $490(71 \%)$ comparison subjects: $\left.\chi^{2}=4.46, P=0.035\right)$. There were differences in occupational characteristics between the two subsamples; only 84 $(33 \%)$ and $64(25 \%)$ of 253 problem users, respectively, had gained any qualification or were currently employed, compared with $222(45 \%)$ and $175(36 \%)$ of 490 in the comparison sample $\left(\chi^{2}\right.$ for any qualification $=11.11, \quad P=0.0009 ; \quad \chi^{2}$ for employed $=8.30, P=0.004)$. The average age of the problem users on leaving school was 15.3 years $($ s.d. $=1.15$ ), as opposed to 15.6 years (s.d. $=1.20$ ) for the social users $(t=4.04$, d.f. $=733, P<0.0001)$.

\section{Clinical characteristics}

Problem users were more likely to report childhood adversity, antisocial behaviour in adolescence and previous self-harm (childhood adversity: 115 of 253 (46\%) problem users, compared with 178 of 490 $(36 \%)$ others on remand, $\chi^{2}=4.95$, $P=0.026$; significant truancy: 168 of 253 (66\%) problem users, compared with 217 of $490(44 \%)$ others on remand, $\chi^{2}=30.05, P<0.0001$; deliberate self-harm: 83 of $253(33 \%)$ problem users, compared with 102 of $490(21 \%)$ others on remand, $\left.\chi^{2}=12.85, P=0.0003\right)$. Similar proportions reported literacy difficulties. Half of the problem users (124 of $252,49 \%$ ) reported past psychiatric treatment, compared with 169 of $490(35 \%)$ comparison subjects $\left(\chi^{2}=17.35, P<0.0001\right)$. The comparison group reported consulting the prison medical officer marginally more often about their physical health than the problem users. The average number of such attendances in the preceding month was 0.90 (s.d. $=2.52$ ) for the comparison group $(n=474)$, and 0.57 (s.d.=1.23) for the problem users $(n=241 ; t=1.93$, d.f. $=713$, $P=0.054$ ). Similar proportions in both groups had received night sedation since imprisonment. The prevalence of mental disorders among all subjects, irrespective of substance misuse, exceeded the figure found in the community (Brooke et al, 1996). There was a difference between the two groups in the prevalence of mood disorder: comparison subjects $(n=453)$ reported 'any depressive illness' in 43 cases $(9.5 \%)$; problem users $(n=239)$ reported 'any depressive illness' in 36 cases $(15.1 \%) ; \chi^{2}=11.35$, d.f. $=5, P=0.045$. We diagnosed a psychotic illness in 36 male prisoners on remand, that is, $4.8 \%$. Of these, 12 were in the 'problem' substance use group, of whom seven had alcohol dependency. These figures suggest that prisons contain significant numbers of unconvicted men with severe and complex psychiatric disorders.

\section{Current well-being}

The SF36 gave an indication of current well-being; it was not administered to the 206 subjects who were under 21 years old. In all the SF36 domains, problem users perceived themselves to be worse than other remand prisoners. In the areas of 'general health' and 'vitality', these differences were significant. (Mean scores for general health: social users, 68.2, s.d.=21.2, $n=284$; problem users, 62.1, s.d. $=25.3, \quad n=156 ; \quad t=2.57, \quad$ d.f. $=275.9$, $P=0.011$. Mean scores for vitality: social users, 54.9, s.d. $=21.1, n=284$; problem users, 48.7, s.d. $=21.2, n=156 ; t=2.96$, d.f. $=437, P=0.003$.)

\section{Patterns of offending; different histories of convictions and imprisonment}

Nearly twice as many problem users had been charged with burglary (70 of 253 (28\%) problem users, compared with 73 of $490(15 \%)$ others on remand, $\left.\chi^{2}=17.51, P<0.0001\right)$, and their offences were more severe. The mean age at first conviction was younger among the problem drug users (14.1 years for comparison cases, s.d. $=2.30, n=286 ; 13.6$ years for problem users, s.d. $=2.0, n=184 ; t=2.43$, d.f. $=468, P=0.016$ ). Problem users were overrepresented among those who had served two or more custodial sentences (comparison cases, $n=172 \quad(36.1 \%)$, problem users, $n=141(59.0 \%) ; \chi^{2}=38.1$, d.f. $=2, P<0.0001$ ).

\section{DISCUSSION}

\section{Limitations of the data}

The data were obtained retrospectively, by self-report, and are therefore subject to bias such as poor recall and a desire for social acceptability; other influences, such as the prison setting and the effect of refusers on the results, have been described by Brooke et al (1998). Addicts in criminal justice settings have been shown to underreport their level of substance misuse (Wish, 1988). However, the availability of prison records and previous reports increases the validity of this study.

This study did not attempt to assess subjects' levels of dependence on cannabis, which, in the light of current understanding about cannabis dependency, would have made a more complete assessment of subjects' difficulties with street drugs.

\section{Vulnerability among prison populations}

In this paper, we drew a distinction between those prisoners who were 'social' users and those whose substance use caused problems. This was a pragmatic choice, because of the difficulty in being more precise about a state, such as 'dependency', with blurred boundaries. This is, perhaps, an artificial distinction; many subjects would have been in a different group if we had interviewed them at a different time. The levels of childhood adversity, disadvantage and instability were high in both groups.

However, the problem users were clearly worse off than their peers. They were a younger group with disproportionate levels of educational failure, unemployment and housing difficulties. Their average ages at first conviction and on leaving school were younger. These findings are in agreement with the most recent large survey of psychiatric morbidity among prisoners (Singleton et al, 1998), which showed that subjects with drug dependency were less likely to be married and less likely to be educated to A-level standard. Problems with substance misuse may be a marker of special susceptibility in this already vulnerable population. Substance misuse has been associated with suicide in prison (Leibling, 1992) and with violence among mentally disordered offenders (Monahan \& Steadman, 1994). 


\section{Are substance misusers in the criminal justice system different?}

The severity of dependence among our subjects who were addicted to opiates equalled that of patients entering in-patient detoxification (Brooke et al, 1998), and imprisonment is a frequent experience among addicts, so it is likely that they are essentially the same population of drug misusers. With reference to those who were dependent on alcohol, Tam et al (1996) showed that problem drinkers who were known only to the criminal justice system (and not to treatment facilities) tended to be younger men who were less dependent. This finding suggests that early intervention packages with controlled drinking guidelines would be appropriate.

\section{Clinical variables}

Half of the remand prisoners with substance problems reported having received psychiatric treatment in the past. Some of this treatment was in substance misuse services. This agrees with previous estimates that half of the addicts in contact with probation services are new to treatment (Advisory Council on the Misuse of Drugs, 1991), despite the efficacy of substance misuse services (Task Force to Review Services for Drug Misusers, 1996).

Within the sample of remand prisoners, the SF36 scores showed that problem users perceived themselves to be less well than other prisoners on remand. Despite this, they were not consulting the prison doctor more often for emotional or physical complaints. They were not receiving night sedation more often. This suggests that their expectations of the services were lower, or that they were not good at making use of them. Bearing in mind that the problem users group contained many prisoners with multiple diagnoses, perhaps those with the greatest need were not using the services enough.

\section{Implications for practice}

Problem users on remand need a range of psychiatric, educational and social interventions. Hodgins \& Lightfoot (1988) divided prisoners with histories of alcohol and drug use into five groups with different social and clinical needs. They suggested specific treatment packages for each group, including general life skills development. The Home Affairs Committee (1999) has stated that these measures are especially relevant to remand and short-term

\section{CLINICAL IMPLICATIONS}

Men remanded in custody with a diagnosis of substance misuse are more likely than other remanded prisoners to have a mood disorder, fewer qualifications, higher levels of unemployment and more housing difficulties.

- Their difficulties have been apparent from their teenage years, if not earlier.

Substance misusers on remand have multiple deficits in skills, and need access to help in many areas, in addition to substance misuse.

\section{LIMITATIONS}

The data were obtained retrospectively, by self-report, and are subject to bias.

The average refusal rate was $18 \%$, which may have introduced bias.

Assessors knew whether the subject had a diagnosis of substance misuse.

DEBORAH BROOKE, CAECILIA TAYLOR, JOHN GUNN, ANTHONY MADEN, Department of Forensic Psychiatry, Institute of Psychiatry, London

Correspondence: Deborah Brooke, The Bracton Centre, Bexley Hospital, Old Bexley Lane, Bexley, Kent DA5 2BW,UK. Tel: 01322 294300; fax: 01322293595

(First received 5 November 1999, final revision 8 February 2000, accepted I0 February 2000)

prisoners, because they are more likely to be in prison for drug-motivated crimes, and treatment is more urgent because they will be released sooner. Other recommendations included improved assessment procedures on induction, and urine screening for all prisoners on reception.

The difficulties reported by the problem users were long-standing. Time in prison can only offer a window of opportunity to start to change. The depth of need and the large numbers imply that prison health care services alone cannot address these problems: a response right across the institution is required. Furthermore, recovery needs to be consolidated after release, so there should be close liaison between services inside and outside prison. This may be facilitated by implementing the recommendation that local health authorities should take into account the health needs of prisoners in their area when commissioning services (HM Prison Service $\&$ the NHS Executive, 1999).

\section{REFERENCES}

Advisory Council on the Misuse of Drugs (1991) Drug Misusers and the Criminal Justice System: Part I:
Community Resources and the Probation Service, p. 23. London: HMSO.

Brooke, D., Taylor, C., Gunn, J., et al (1996) Point prevalence of mental disorder in unconvicted male prisoners in England and Wales. British Medical Journal, 313, 1524-1527

$\ldots, \ldots, \ldots$, et al (1998) Substance misusers remanded to prison - a treatment opportunity? Addiction, 93 $1851-1856$.

HM Prison Service \& the NHS Executive (1999) The Future Organisation of Prison Health Care; A Report by the Joint Prison Service and National Health Service Executive Working Group. London: Department of Health.

Hodgins, D. \& Lightfoot, L. (1988) Types of male alcohol- and drug-abusing incarcerated offenders. British Journal of Addiction, 83, 1201-1213.

Home Affairs Committee, House of Commons (1999) Session 98-99, Fifth Report: Drugs and Prisons, Vol. I. London: Stationery Office.

Home Office (1994) Statistical Bulletin, Issue 16/94 London: Home Office.

Leibling, A. (1992) Suicides in Prison, p. 135. London: Routledge.

Maden, A., Taylor, C., Brooke, D., et al (1996) Mental Disorder in Remand Prisoners. London: Home Office.

Mayfield, D., Mcleod, G. \& Hall, P. (1974) The CAGE questionnaire: validation of a new alcoholism screening instrument. American Journal of Psychiatry, I3I, $\mid 121-1123$.

McHorney, C. A., Ware, J. E. \& Raczek, A. E. (1993) The MOS 36 -item short-form health survey: II. Psychometric and clinical tests of validity in measuring 
physical and mental health constructs. Medical Care, $3 \mathbf{1}$ 247-263.

Monahan, J. \& Steadman, H. (1994) Violence and Mental Disorder, p. II4. Chicago: University of Chicago Press.

Singleton, N., Meltzer, H. \& Gatward, R. (1998)

Psychiatric Morbidity among Prisoners in England and Wales (Office for National Statistics). London: The Stationery Office.
Tam, T., Schmidt, L. \& Weisner, C. (1996) Patterns in the institutional encounters of problem drinkers in a community human services network. Addiction, 91, 657-669.

Task Force to Review Services for Drug Misusers (1996) Report of an Independent Review of Services for Drug Misusers in England. London: Department of Health

Ware, J. E. \& Sherbourne, C. D. (1992) The MOS 36 -item short-form health survey: I. Conceptual framework and item selection. Medical Care, 30, 473-483.

Wish, E. (1988) Identifying drug-abusing criminals. In Compulsory Treatment of Drug Abuse: Research and Clinical Practice (eds C. Leukefeld \& F. Tims), p. 143. NIDA Research Monograph 86. Rockville, MD: National Institute on Drug Abuse.

World Health Organization (1992) The ICD-IO Classification of Mental and Behavioural Disorders. Geneva: WHO. 